\title{
Strong link between coronavirus count and bad air: a case study of India
}

\author{
Sneha Gautam ${ }^{1} \cdot$ Cyril Samuel $^{1,2} \cdot$ Alok Sagar Gautam $^{2}$ (D) Sanjeev Kumar ${ }^{2}$
}

Received: 7 November 2020 / Accepted: 22 March 2021 / Published online: 3 April 2021

(c) The Author(s), under exclusive licence to Springer Nature B.V. 2021

\begin{abstract}
The present study aims to highlight the contrast relationship between COVID-19 (Coronavirus Disease-2019) infections and air pollutants for the Indian region. The COVID-19 data (cumulative, confirmed cases and deaths), air pollutants $\left(\mathrm{PM}_{10}, \mathrm{PM}_{2.5}, \mathrm{NO}_{2}\right.$ and $\mathrm{SO}_{2}$ ) and meteorological data (temperature and relative humidity) were collected from January 2020 to August 2020 for all 28 states and the union territory of India during the pandemic. Now, to understand the relationship between air pollutant concentration, meteorological factor, and COVID-19 cases, the nonparametric Spearman's and Kendall's rank correlation were used. The COVID-19 shows a favourable temperature (0.55-0.79) and humidity (0.14-0.52) over the Indian region. The $\mathrm{PM}_{2.5}$ and $\mathrm{PM}_{10}$ gave a strong and negative correlation with COVID-19 cases in the range of 0.64-0.98. Similarly, the $\mathrm{NO}_{2}$ shows a strong and negative correlation in the range of 0.64-0.98. Before the lockdown, the concentration of pollution parameters is high due to the shallow boundary layer height. But after lockdown, the overall reduction was reported up to $33.67 \%$ in air quality index (AQI). The background metrological parameters showed a crucial role in the variation of pollutant parameters $\left(\mathrm{SO}_{2}, \mathrm{NO}_{2}, \mathrm{PM}_{10}\right.$ and $\left.\mathrm{PM}_{2.5}\right)$ and the COVID-19 infection with the economic aspects. The European Centre for Medium-Range Weather Forecasts derived monthly average wind speed was also plotted. It can see that January and February of 2020 show the least variation of air mass in the range of 1-2 m/s. The highest wind speed was reported during July and August 2020. India's western and southern parts experienced an air mass in the range of 4-8 m/s. The precipitation/wet deposition of atmospheric aerosols further improves the AQI over India. According to a study, the impact of relative humidity among all other metrological parameters is positively correlated with Cases and death. Outcomes of the proposed work had the aim of supporting national and state governance for healthcare policymakers.
\end{abstract}

Keywords COVID-19 · Air pollutants · Chronic exposure · Meteorological factor · India

Sneha Gautam

snehagautam@karunya.edu; gautamsneha@gmail.com

$\triangle$ Alok Sagar Gautam

phyalok@gmail.com

1 Karunya Institute of Technology and Sciences, Coimbatore 641114, Tamil Nadu, India

2 Department of Physics, HNB Garhwal University, Srinagar, Garhwal, Uttarakhand, India 


$\begin{array}{ll}\text { Abbreviations } \\ \text { COVID-19 } & \text { Coronavirus diseases-2019 } \\ \text { WHO } & \text { World health organization } \\ \text { ECMWF } & \text { European centre for medium-range weather forecasts } \\ \text { CPCB } & \text { Central pollution control board } \\ \text { PM } & \text { Particulate matter } \\ \text { MPs } & \text { Meteorological parameters } \\ \text { AQI } & \text { Air quality index } \\ \text { IGP } & \text { Indian Gangetic plain } \\ \text { Max } & \text { Maximum } \\ \text { Min } & \text { Minimum } \\ \text { Ave } & \text { Average levels of variables } \\ \text { RH } & \text { Relative humidity } \\ \text { T } & \text { Temperature }\end{array}$

\section{Introduction}

In late December 2019, many cases related to pneumonia were reported due to infection to novel coronavirus in Wuhan City, China (Gautam, Dilwaliya, et al., 2020; Gautam, Joshi, et al., 2020; WHO, 2020a; Wu et al., 2020). According to Xu et al. (2020), novel coronavirus was identified as SARS-CoV-2 for its likeness with SARS (severe acute respiratory syndrome) in 2002-2003. Many studies (Bherwani et al., 2021; Chen et al., 2017; Sohrabi et al., 2020) reported that the possible effects (i.e. respiratory problems, organ failure, pneumonia, etc.) had been identified in people affected by SARS-CoV-2 infections. In this regard, older individuals having severe symptoms are the primary cases with previous comorbidities (i.e. respiratory diseases, cardiovascular, etc.) (Changotra et al., 2020; Wang et al., 2020). The worst scenario was observed by the World Health Organization (WHO), and they declared it a pandemic disease with the acronym COVID-19 for coronavirus disease 2019 (WHO, 2020b). The Chinese government has taken initial actions, unfortunately, these steps were botched to control the diffusion of coronavirus, moreover have spread globally within a short time.

Figure 1 presents the transmission classification with different categories (i.e. community transmission, a cluster of cases, sporadic cases, no cases, and pending). In the present study, we are highlighting the Indian region with few points, these are: (i) India is growing very fast with positive cases; (ii) India is now in the second stage (cluster cases); (iii) India is one of the most polluted countries in the world; (iv) India is the only country affected by COVID-19 in south Asia region even more extensive than that initially identified in China. On the other hand, different countries like the USA, Brazil, Russia, etc., are rapidly registered with the exponential growth of positive cases and deaths. However, all possible measures (i.e. lockdowns, social distancing, etc.) have been applied to prevent or break the chain of COVID-19 (ECDC, 2020). The recent update from WHO has released confirmed cases $(25,327,098)$, including deaths $(848,255)$ worldwide.

On the other side, many studies (Ambade et al., 2021; Bashir, 2020; Dutheil et al., 2020; Frontera et al., 2020; Zhu et al., 2020) have been done on the potential correlation between COVID-19 outbreaks and air pollutants. Moreover, every country has prepared the documentary on SARS-CoV-2 diffusion and pandemic has been stated; however, a discussion is pending about the number of death cases or death rate and severity of pneumonia 


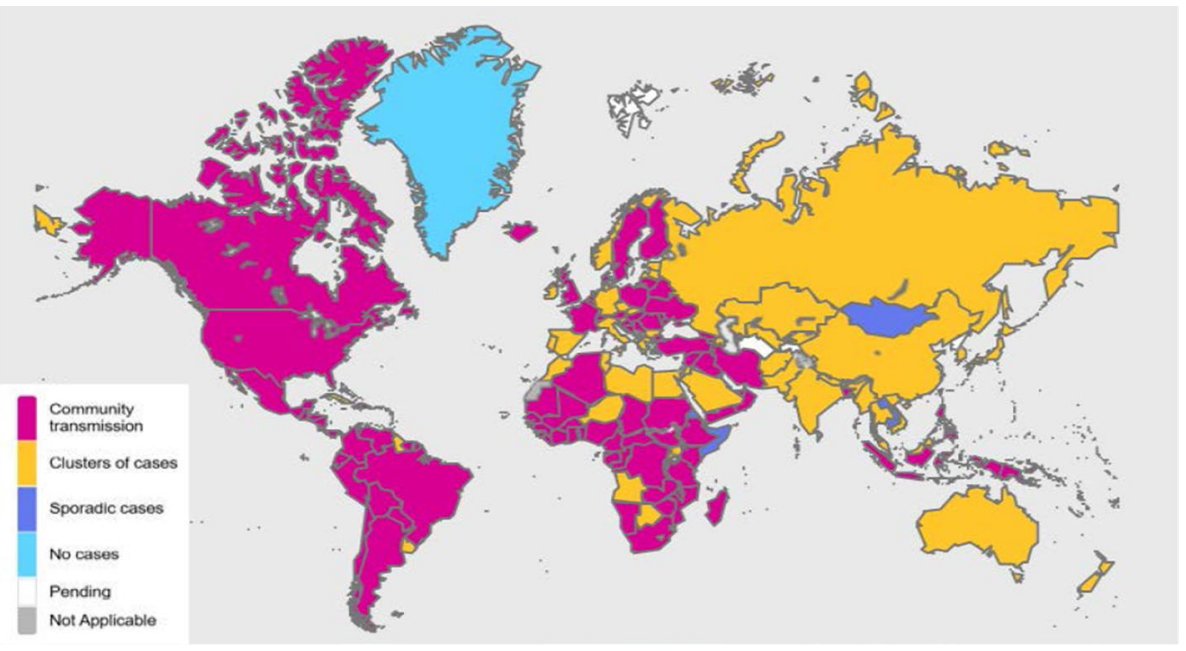

Fig. 1 A schematic diagram of transmission classification of COVID-19 (Source: WHO, 2020b)

encountered in few particular countries (i.e. China, Italy, India, USA, etc.) (WHO, 2020a). In India, COVID-19 is in the second phase (clusters of cases) where few states (i.e. Maharashtra, Andhra Pradesh, Tamil Nadu, Karnataka, Uttar Pradesh, New Delhi) have been reported a majority of positive cases. The total number of confirmed cases and cumulative deaths makes approximately 50\% of COVID-19 instances in the Indian region. This information indicates to a precise point of the selected states that may allow for the spreading of the novel coronavirus. From an air quality point of view, the mentioned states are well known to be Indian states having the highest polluted cities or highest pollution levels. Here, we investigate the link between air pollutants and the severity of novel coronavirus, which could have vital indications towards managing the current situation and preventing the pandemic.

\section{Materials and methods}

\subsection{Sample and data}

The COVID-19 related data (i.e. positive cases, cumulative cases, new death cases, and cumulative cases) have been collected from the WHO (https://covid19.who.int/). Air pollutants (i.e. $\mathrm{PM}_{2.5}, \mathrm{PM}_{10}, \mathrm{SO}_{2}, \mathrm{NO}_{2}$ ) data and meteorological parameters (MPs) (i.e. temperature, humidity) have been collected from the Indian government organization called Central Pollution Control Board (CPCB) (https://cpcb.nic.in/). The data for monthly wind patterns were extracted from European Centre for Medium-Range Weather Forecasts (ECMWF) platform (Patel \& Kumar, 2015) and plotted by using GRADS software. We have collected the data from the 21 states and union territories (which have at least one monitoring station) to obtain the average values of India for the measured variables in the particular month(Also explained in Fig. 2).

Measures of variables: We have used air quality index (AQI), $\mathrm{PM}_{2.5}, \mathrm{PM}_{10}, \mathrm{SO}_{2}, \mathrm{NO}_{2}$, $T, \mathrm{RH}$, wind speed and wind direction as a measured variables in the presented manuscript. 


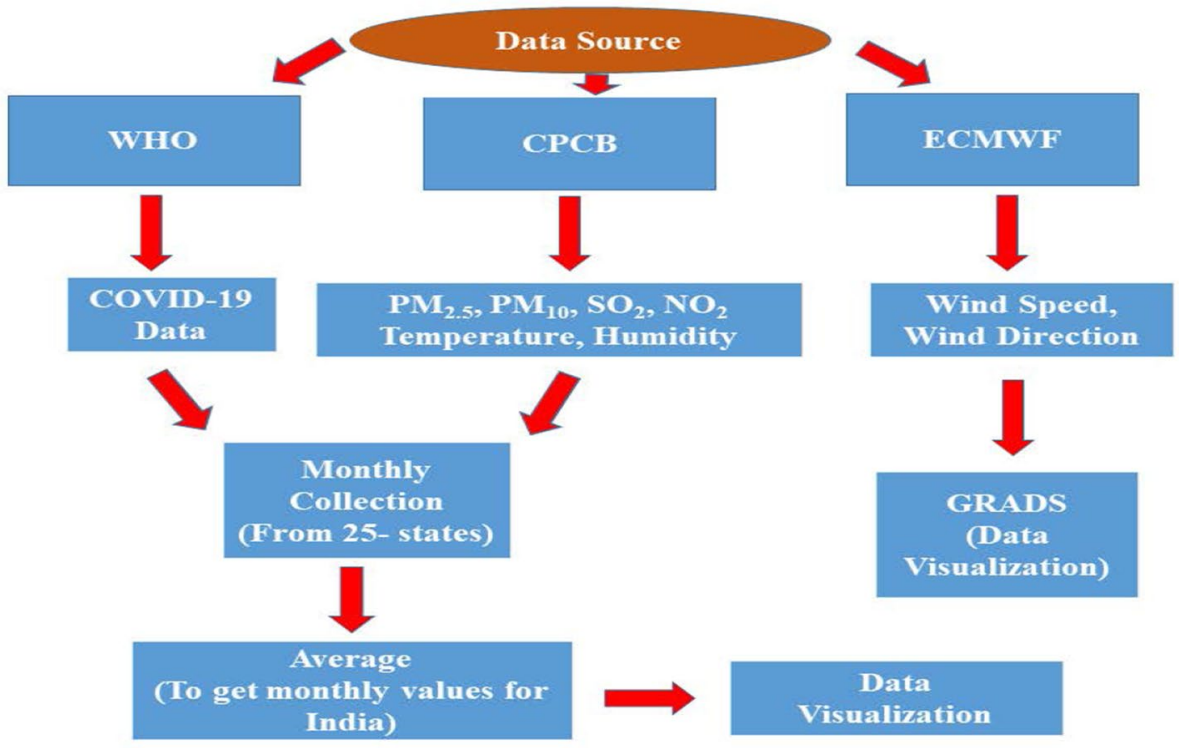

Fig. 2 Flow chart of data extraction and processing

\subsection{Techniques and data analysis}

Spearman's and Kendall's rank correlation was calculated to determine the nature of the association between the parameters. The nonparametric Spearman's rank correlation can be evaluated by using the following mathematical relation:

$$
r_{s}=1-6 \times \frac{\sum d_{i}^{2}}{n\left(n^{2}-1\right)}
$$

where $\boldsymbol{d}_{\boldsymbol{i}}=$ Difference between the rank of two parameters, $\boldsymbol{n}=$ Number of alternatives.

The correlation coefficients lie in the typical range -1 (Positive correlation) to +1 (Negative correlation).

Whereas, Kendall's rank correlation is also a nonparametric test that estimates the ordinal association between variables. The mathematical equation for Kendall's rank correlation is given by the following relation:

$$
\tau=\frac{[(\text { concor })-(\text { discor })]}{0.5 \times n \times(n-1)}
$$

where concor $=$ Number of concordant, discor $=$ Discordant pairs and $n=$ number of pairs. The value of $\boldsymbol{\tau}$ also ranges from -1 to +1 similar to Spearman's coefficient $\left(r_{\mathrm{s}}\right)$. The calculation of correlation coefficients and $p$ values was performed by using HIMSC and MASS packages in $R$ as suggested by the Gautam, Dilwaliya, et al. (2020)), Gautam, Joshi, et al. (2020)), Kumar, Hama, et al. (2020) and Kumar, Lin, et al. (2020).

For the assessment of the impact of lockdown enforced due to COVID-19, the air quality index (AQI) is also calculated using the methodology suggested by the (Gautam, Dilwaliya, et al., 2020; Gautam, Joshi, et al., 2020; Mahato et al., 2020) in their 
study. The Indian AQI system is defined as impact of individual pollutants on human health, which is combinations of two steps involvements (a) formation of individual sub-indices (SIs) of pollutants and (b) combination of sub-indices to obtain AQI. The SIs $\left(I_{1}, I_{2}, \ldots, I_{N}\right)$ for $N$ pollutant $\left(X_{1}, X_{2}, \ldots, X_{N}\right)$ is calculated by using sub-index functions as follows:

$$
I_{i}=f\left(X_{i}\right)
$$

where $i=1,2, \ldots, N$

Now Aggregation of sub-indices $\left(I_{i}\right)$ is calculated by using the following mathematical function (given below)

$$
I=F\left(I_{1}, I_{2}, \ldots, I_{N}\right)
$$

The mathematical expression for sub-index $\left(I_{p}\right)$ of known pollutant concentration $\left(C_{p}\right)$ is given by

$$
I_{p}=\left[\left\{\frac{I_{\mathrm{HI}}-I_{\mathrm{LO}}}{B_{\mathrm{HI}}-B_{\mathrm{LO}}}\right\} \times\left(C_{p}-B_{\mathrm{LO}}\right)\right]+I_{\mathrm{LO}}
$$

$B_{\mathrm{HI}}=$ Breakpoint concentration greater or equal to given concentration,

$B_{\mathrm{LO}}=$ Breakpoint concentration smaller or equal to given concentration,

$I_{\mathrm{HI}}=\mathrm{AQI}$ value corresponding to $B_{\mathrm{HI}}$,

$I_{\mathrm{LO}}=\mathrm{AQI}$ value corresponding to $B_{\mathrm{LO}}$.

Furthermore;

$$
\mathrm{AQI}=\operatorname{MAX}\left(I_{p}\right)
$$

where $p=1,2, \ldots, N$.

Mahato et al. (2020) (National Air Quality Index. Central Pollution Control Board, 1-44).

\section{Result and discussion}

The present trend in the Indian region straightaway revealed potential differences at the regional level for reporting cases or infections of a virus. The probably massive number of positive instances concentrated, especially in the northern part of India (Bherwani et al., 2020; Gupta et al., 2020). The number of COVID-19 positive (new and cumulative) and deaths (new and incremental) cases reported from January 2020 to August 2020 is presented in Fig. 3 (data re-elaborated from the official daily reports of WHO 2020; Data assessed on September 3, 2020). Figure 3b and c shows that the approximate number of COVID-19 positive cases and death cases due to COVID-19 in India are $>300,000$ and $>10,000$, respectively.

The two-point segment graph is presented in Fig. 3c, where it can be easily found that positive cases have been increased from April and its very high in August and so on. Similarly, the rate of deaths is growing with time; however, the death ratio, according to the number of positive cases, $1.78 \%$ (new cases and new deaths), and $2.19 \%$ (cumulative positive cases and cumulative deaths) only (Fig. 3c, d). Many studies (Bukhari \& Jameel, 2020; Liu et al., 2020; Wang et al., 2020) indicated that confirmed positive cases were observed 

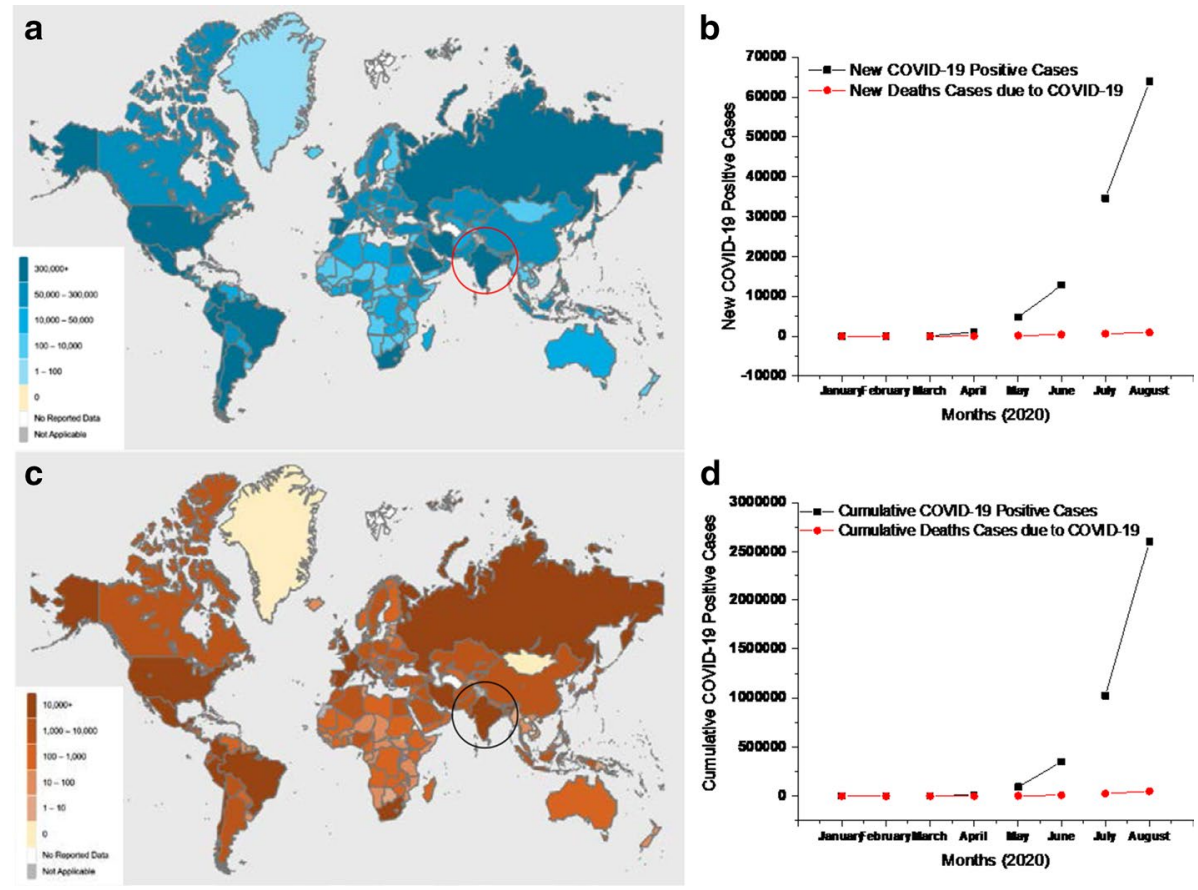

Fig. 3 Distribution of COVID-19 outbreak in India (January-August 2020). a An absolute number of positive cases (new and cumulative cases); b the Absolute number of deaths due to COVID-19 (recent deaths and cumulative deaths); c Two-point segment comparison between new COVID-19 positive cases and recent Deaths due to COVID-19 and d Two-point segment comparison between new deaths cases and cumulative deaths cases due to COVID-19

in lower temperatures. In contrast to the reported all studies, it can be simply observed the confirmed cases are higher in number, especially in summer or dry season (Fig. 2c, d).

In this regard, a comprehensive analysis should be done to understand the relationship between meteorological factors and air pollutants to transmit a novel coronavirus in the Indian region. We collected the air pollutants and MPs data sets from the Central Pollution Control Board (CPCB), Indian government organization, and summarized in Fig. 4a and b.

From Fig. 4a, as many Indian studies (Bherwani et al., 2020; Gautam, Dilwaliya, et al., 2020; Gautam, Joshi, et al., 2020; Gupta et al., 2020) suggested on air quality and lockdown, it can be seen that the sudden fall of air pollutants due to lockdown applied during the pandemic, especially in between late March and April. On the other side, the ion and mass concentration of air pollutants is affected by ambient temperature $(T)$ and relative humidity (RH) (Liu et al., 2020; Chow et al., 2015). Therefore, we have collected the data sets of $T$ and RH along with air pollutant data to understand the role of air pollution in COVID-19 outbreak risk, especially in the Indian region. The ambient $T$ and RH showed the ambient atmosphere's general profile, where they are offering a reverse relationship with each other (Fig. 4b). Some studies have shown that air pollutant's concentration changes smoothly as atmospheric $T$ and RH increases or decreases (Chan et al., 1992; Pathak et al., 2004). That means variation in $T$ and RH might play a significant role in changing air pollutant concentrations. (Xie \& Zhu, 2020) obtained the threshold value of $T$ at $3^{\circ} \mathrm{C}$ by using the response curve COVID-19. MPs such as wind direction, wind speed, 

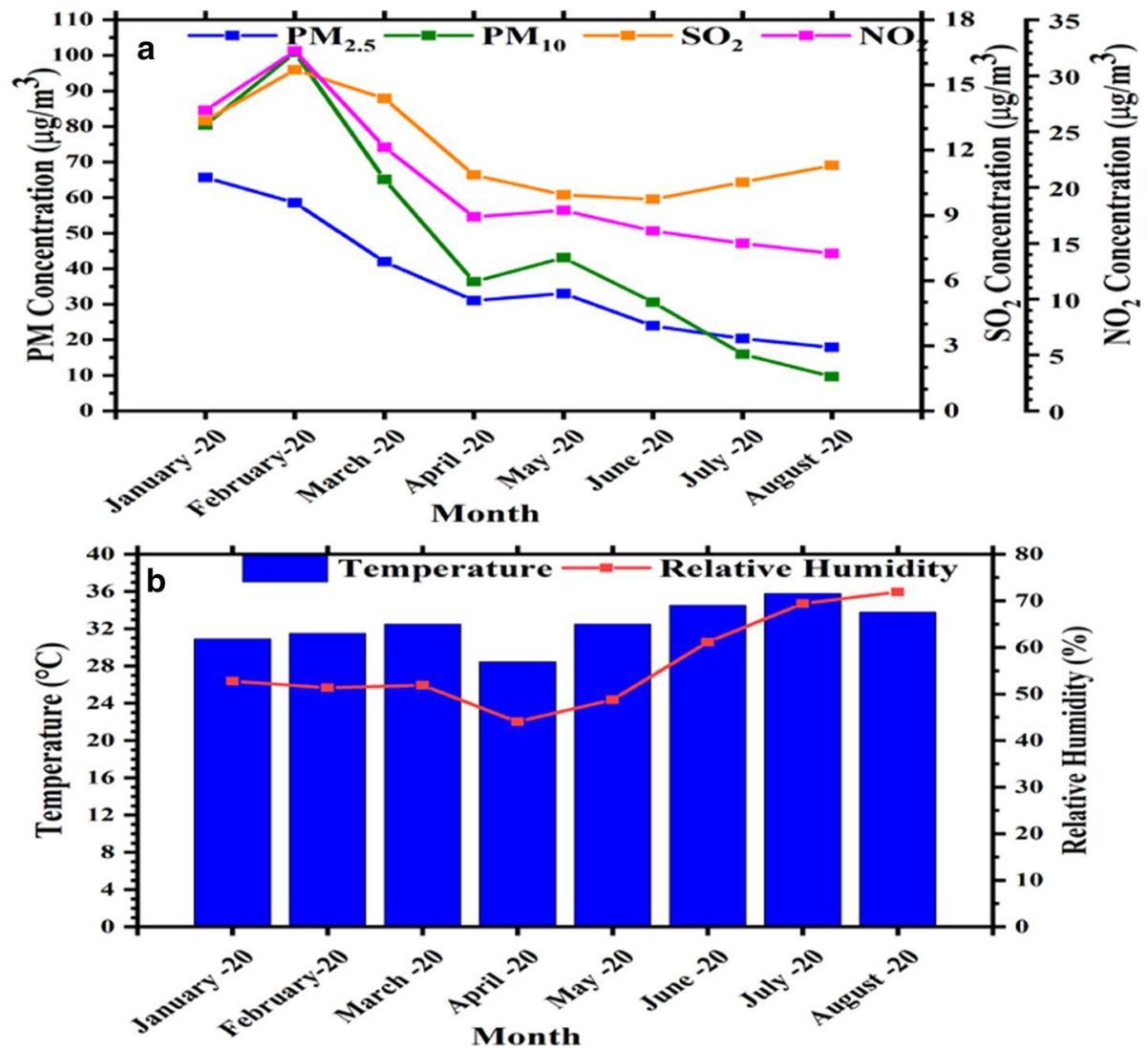

Fig. 4 Variation of the concentration profile of air pollutant $\mathbf{a}$ and meteorological parameters $\mathbf{b}$ during pandemic (January-August 2020)

$T$, rain fall, pressure, solar radiation, etc. have the impacts on the removal, dispersion and chemical formation of the particulate matters (PMs). Few studies have reported a significant linkage of PM concentration and MPs. $\mathrm{PM}_{10}$ mass concentrations decreased due to an increase of $T$, wind speed and precipitation (Keary et al., 1998). Negative correlation of $\mathrm{PM}_{10}$ and temperature is due to traffic density and domestic heating during winter (Keary et al., 1998). Relationship of five MPs and total suspended particles (TSP) showed the low correlations during winter at Elaziğ city (Turkey) as reported by (Akpinar et al., 2008). Yadav et al. (2015) also performed a model based study to understand the variation of PM and MPs over Pune (India).

The monthly AQI shows a remarkable variation in due lockdown across India (Fig. 5). Before lockdown, the AQI varies in the range of $91.45 \pm 45.21$ to $285.40 \pm 75.30$ with an average (mean + standard deviation) of 174.19 \pm 99.42 , but after lockdown, the AQI levels has been drastically changed in the range of $41.87 \pm 20$ to $75.87 \pm 42.2$ with an average value $58.66 \pm 8.5$. The overall reduction in the pandemic periods (January-August 2020) was reported by up to $33.67 \%$ over India.

Maji et al. (2015) estimate the trends of air quality from 2001 to 2010 and also explained the seasonal and monthly variation of AQI over Delhi based on CPCB datasets. (Garg \& 


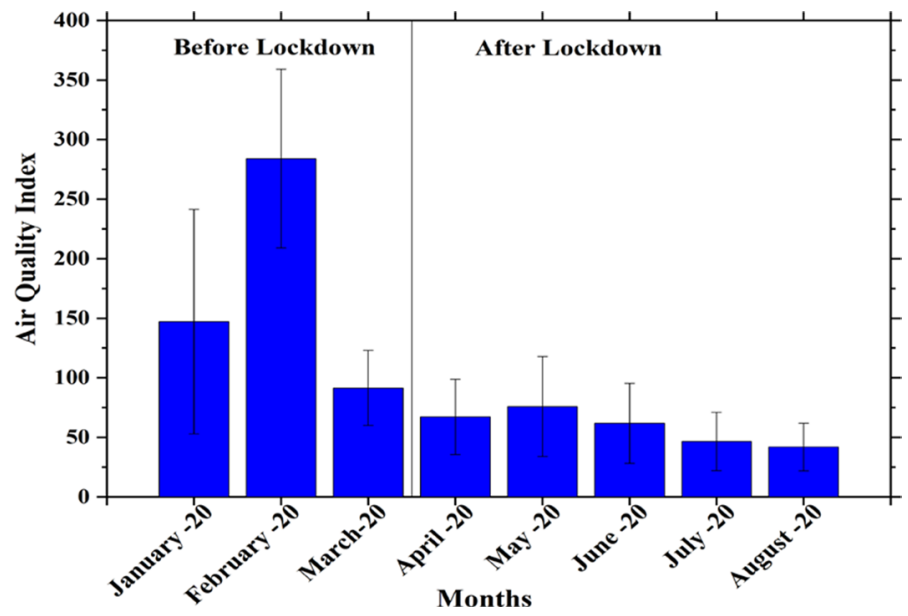

Fig. 5 Monthly variation of the air quality index (AQI) during pandemic (January-August 2020)

Gupta, 2020) also, study the monthly variation of AQI during different months and applied the statistical approach to determine the responsible sources to degrade the AQI during 2017 over Delhi. The lower values of AQI in June, July and August 2020 are also explained in the upcoming sections.

The monthly average wind pattern is also plotted in Fig. 6 by using the ECMWF data set over India. In January (a) and February (b), the variation of air mass over the Indian subcontinents is relatively low. The air mass is blowing in the range of 1-2 m/s over India excepts some parts of Tamilnadu, Gujrat, Rajasthan and Delhi non-capital region in the typical range of 2-3 m/s. During this period (January and February 2020), the concentration of pollution parameters is high due to boundary layer dynamic (Allabakash \& Lim, 2020). In March (c) and April (d), the average wind speed is slightly increased mainly over the western part of Gujrat, Tamilnadu and Indian Gangetic Plain (IGP) in the range of $2-3 \mathrm{~m} / \mathrm{s}$, but the dominantly the air mass is coming from the westerly-north westerly. But in May (e) and June (f) 2020, most of the air mass is blowing range of $2-7 \mathrm{~m} / \mathrm{s}$ over the western and southern part of India.

Now in July (g) and August 2020 (h), the wind speed was high as compared to previous months. The western and southern parts of India experienced an air mass in the range of 4-8 m/s. The air mass from south-southwest usually dominants during June, August and September 2020. The South- south-westerly wind picks moisture from the Indian Ocean and leads to heavy precipitation over India. The process of precipitation/wet deposition of atmospheric aerosols helps to improve the AQI over India (Fig. 5) during monsoon (Garg \& Gupta, 2020; Mamta \& Bassin, 2010; Patel \& Kumar, 2015). Coccia (2020) has examined the spread of COVID-19 with concentration of pollutants and wind speed over Italy and showed the higher risk of COVID-19 infections at low wind speed and high concentration of pollutants. The high wind speed and temperature play important role in the reduction of COVID-19 infections in Brazil. It is clear that wind speed playing a crucial role in the spread process of COVID-19 in the India.

Babu et al. (2020) obtained a significant positive correlation of wind speed and COVID19 daily cases over Delhi, which indicate that the higher wind speed is helpful to spreading over Delhi. 


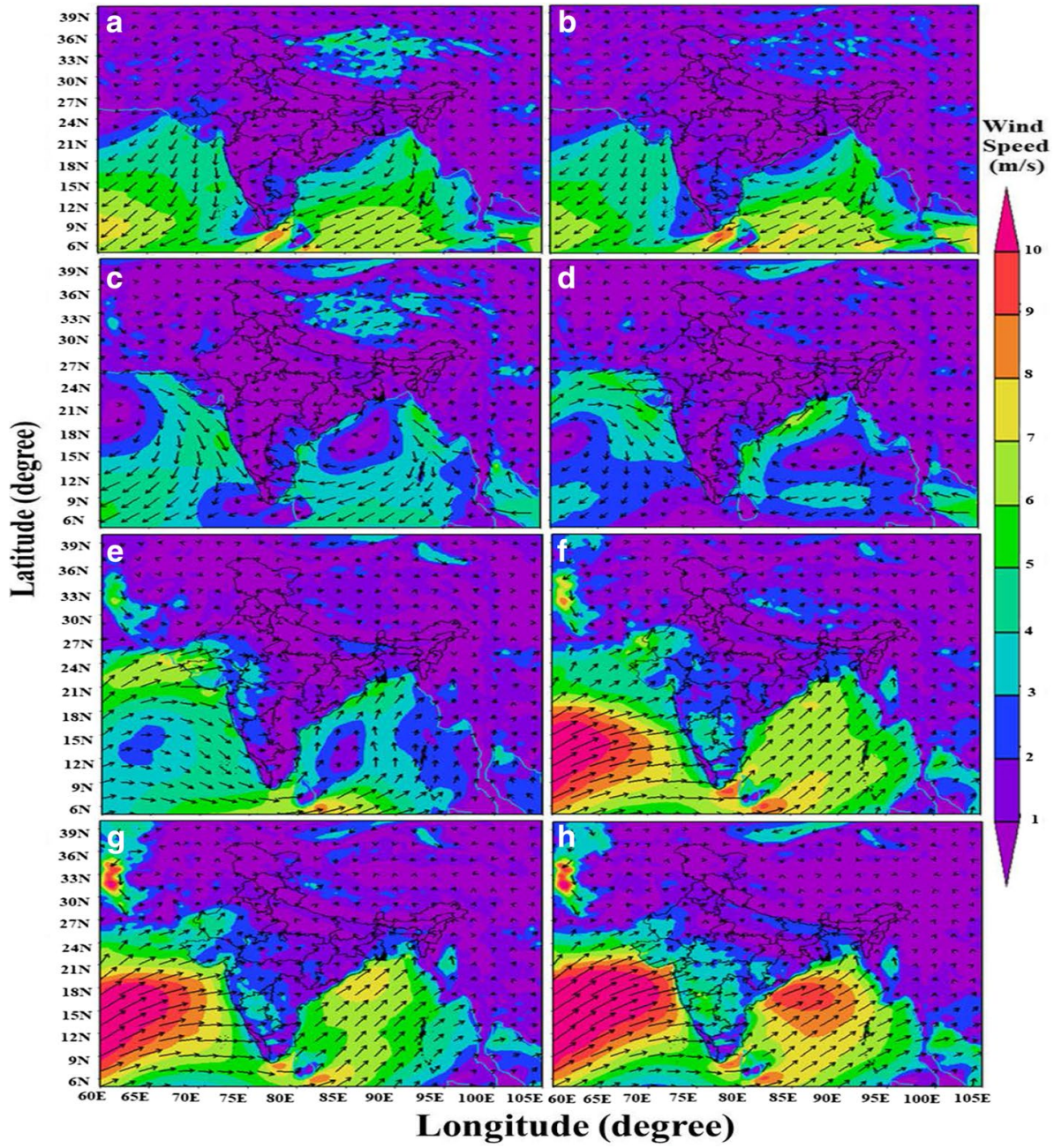

Fig. 6 Variation of monthly wind patterns in months of January (a), February (b), March (c), April (d), May (e), June (f), July (g) and August 2020 (h) over Indian subcontinent during pandemic (January-August 2020)

The COVID-19 (New Cases, Cumulative Cases, New Deaths and Cumulative Deaths) cases show a strong and positive with maximum, average and minimum values of temperature (Table 1). The average temperature shows a stronger correlation ( $r$ values $=0.57-0.79$ ) than maximum $(r=0.50-0.71)$ and the minimum $(r=0.55-0.78)$ temperature, which means at the lower and higher $T$ the COVID-19 cases are less as compare average $T$ range. A similar pattern of variation of $T$ was also reported by (Gautam, Dilwaliya, et al., 2020; Gautam, Joshi, et al., 2020) over India. The RH shows a positive but weak correlation with COVID-19 cases in the range of 0.14-0.52 during observation. The fine particulate $\left(\mathrm{PM}_{2.5}\right)$ gives a strong and negative correlation with COVID-19 cases in the range of -0.90 to -0.98 for the Spearman and -0.64 to -0.91 for the Kendall correlations during calculations (Kumar, Hama, et al., 2020; Kumar, Lin, et al., 2020). The average $\mathrm{PM}_{2.5}\left(\mathrm{PM}_{2.5}\right.$ 


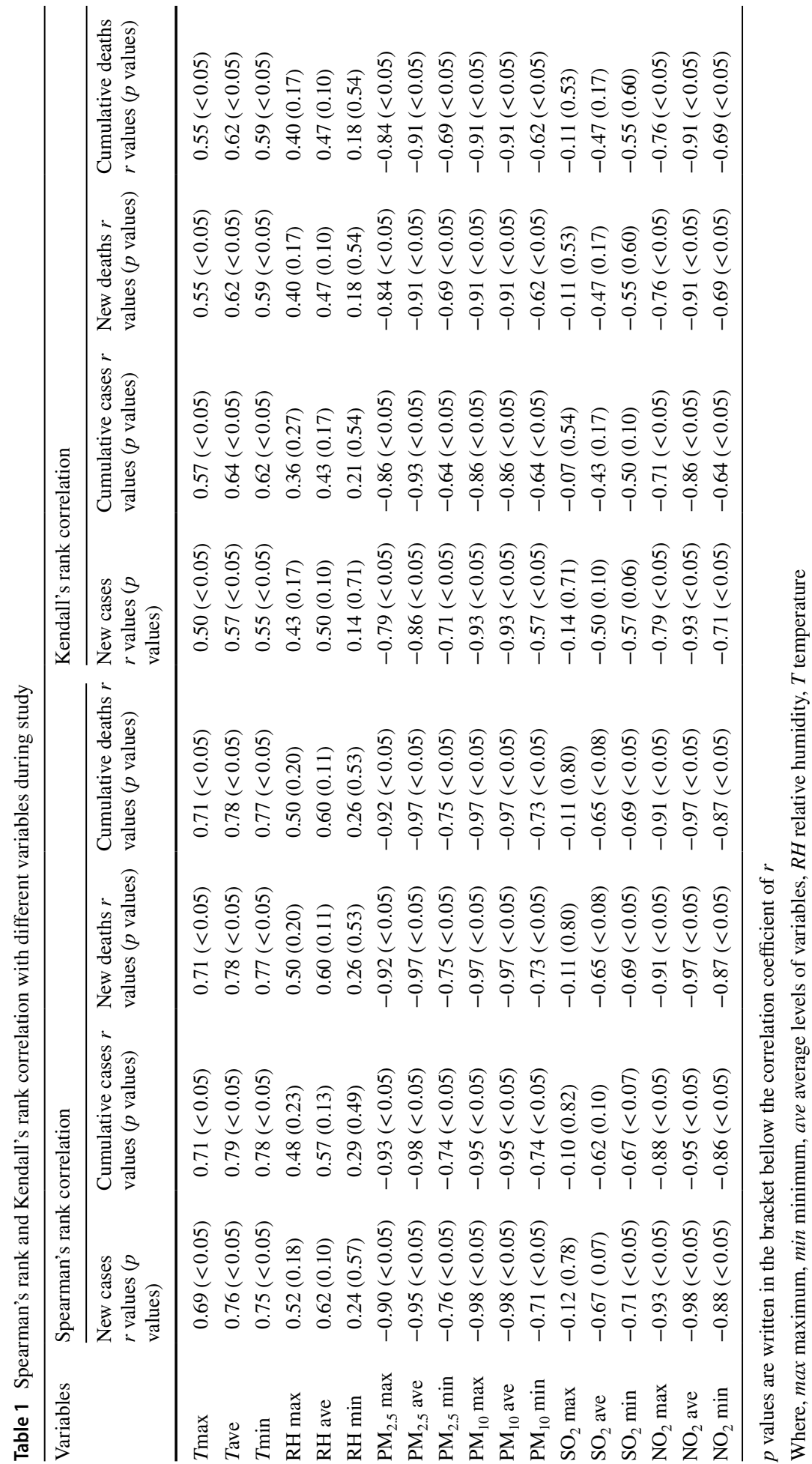


ave) shows a relatively high correlation than minimum $\mathrm{PM}_{2.5}\left(\mathrm{PM}_{2.5} \mathrm{~min}\right)$ and maximum $\mathrm{PM}_{2.5}\left(\mathrm{PM}_{2.5}\right.$ Max) with COVID-19 cases (Table 1), whereas in the case of PM 10 , show a strong and negative correlation at the higher $\left(\mathrm{PM}_{10} \max \right)$ and average $\left(\mathrm{PM}_{10}\right.$ ave $)$ levels. At the lower $\left(\mathrm{PM}_{10} \mathrm{~min}\right)$ levels, the correlation is relatively weaker. Similarly, the $\mathrm{NO}_{2}$ also, shows a strong and negative variation of correlations in the range of 0.64-0.98, it means at more than average levels of PM $\left(\mathrm{PM}_{10}\right.$ and $\left.\mathrm{PM}_{2.5}\right)$ and $\mathrm{NO}_{2}$ the COVID-19 cases are less (Fig. 3c, d) as compared to lower levels of $\mathrm{PM}_{10}$ and $\mathrm{PM}_{2.5}$. But $\mathrm{SO}_{2}$ shows negative and non-significant correlations with COVID-19 cases in the range of 0.10-0.69 during the study, however, at lower $\mathrm{SO}_{2}\left(\mathrm{SO}_{2} \mathrm{~min}\right)$ levels some significant correlation was also observed (Table 1). Kumar, Hama, et al. (2020), Kumar, Lin, et al. (2020) estimate health and economic impacts due to reduction in the $\mathrm{PM}_{2.5}$ concentration during lockdown period over Delhi, Mumbai, Bangalore, Kolkata and Chennai and found that this reduction in $\mathrm{PM}_{2.5}$ can prevent 630 premature deaths worth of 0.63 billion US Dollar (USD). Tanvir et al. also observed a negative correlation between COVID-19 cases and PM over Italy.

\section{Conclusion}

An association between air pollution, COVID-19 confirmed cases, and meteorological factors $(T$ and $\mathrm{RH})$ is plausible. This may have a potential impact on the transmission of the virus and the high rate of infection and mortality. In conclusion, it is observed that infectious diseases come to society with one of the key challenges during a pandemic that has a strong correlation between the periodic emergence of viral agents and socio-economic and environmental factors.

To understand the relationship between air pollutant concentration, meteorological factor, and COVID-19 cases, the nonparametric Spearman's and Kendall's rank correlation were calculated. The COVID-19 shows a strong and positive with $T$ in the range of $0.55-0.79$ over the Indian region. The outcomes indicate that the cumulative death and cumulative cases are increasing rapidly with $T$ and $\mathrm{RH}$. The RH shows a positive but weak correlation with COVID-19 cases in the range of 0.14-0.52. The $\mathrm{PM}_{2.5}$ gives a strong and negative correlation with COVID-19 cases in the range of -0.64 to -0.98 during calculations Similarly, the $\mathrm{NO}_{2}$ shows a strong and negative variation of correlations in the range of 0.64-0.98, which indicates that before lockdown (January-March 2020) the levels of $\mathrm{PM}\left(\mathrm{PM}_{10}\right.$ and $\left.\mathrm{PM}_{2.5}\right)$ and $\mathrm{NO}_{2}$ were high. Before the lockdown, the concentration in the pandemic periods (January-August 2020) was reported by up to $33.67 \%$ over India. The background MPs (wind Speed, wind direction, $T$ and RH) play a very crucial role in the variation of pollution parameter and strongly influence the COVID-19 cases in India. The improvements in the levels of pollution parameters influenced the health and economic aspects due to lockdown.

The monthly ECMWF derived average wind speed is relatively low in January and February in the range of 1-2 m/s over India, except some parts of Tamilnadu, Gujrat, Rajasthan and Delhi non-capital region in the typical range of $2-3 \mathrm{~m} / \mathrm{s}$. But in July and August 2020, the western and southern parts of India experienced an air mass in the range of 4-8 m/s. The south-southwest during June August and September 2020 helps to reduce the AQI due to heavy precipitation. Policy and Managerial Implications: The proposed work's primary purpose has only supported state, national governance for future healthcare policy. The 
MPs and pollution parameters have a significant role in the spread of COVID-19 cases so policy-maker should consider impact of both parameter during making the policy.

Acknowledgements SG is thankful to the World Health Organization, Central Pollution Control Board, Karunya University, Coimbatore, Tamil Nadu, India, to provide us the required data sets and support during analysis. ASG and SK would like to thank the Department of Science and Technology, Government of India for funding support under, Climate Change Programme (CCP), SPLICE Division, Department of Science \& Technology, Technology Bhavan, New Mehrauli Road, New Delhi-110 016 (DST/CCP/ Aerosol/83/2017(G)). ASG would like to thank Vice-Chancellor, HNBGU Srinagar, and Head, Department of Physics, HNBGU Srinagar for providing the necessary infrastructure facility and guidance for this study.

\section{References}

Akpinar, S., Oztop, H. F., \& Akpinar, E. K. (2008). Evaluation of relationship between meteorological parameters and air pollutant concentrations during winter season in Elaziğ, Turkey. Environmental Monitoring Assessment, 146, 211-224. https://doi.org/10.1007/s10661-007-0073-9.

Allabakash, S., \& Lim, S. (2020). Climatology of planetary boundary layer height-controlling meteorological parameters over the Korean Peninsula. Remote Sensing. https://doi.org/10.3390/RS12162571.

Ambade, B., Sankar, T. K., Kumar, A., Gautam, A. S., \& Gautam, S. (2021). COVID-19 lockdowns reduce the Black carbon and polycyclic aromatic hydrocarbons of the Asian atmosphere: Source apportionment and health hazard evaluation. Environment Development and Sustainability. https://doi.org/10. 1007/s 10668-020-01167-1.

Arora, A. S., Rajput, H., \& Changotra, R. (2020). Current perspective of COVID-19 spread across South Korea: Exploratory data analysis and containment of the pandemic. Environmental Development and Sustainability. https://doi.org/10.1007/s10668-020-00883-y.

Babu, S. R., Rao, N. N., Kumar, S. V., Paul, S., \& Pani, S. K. (2020). Plausible role of environmental factors on COVID-19 transmission in the Megacity Delhi, India. Aerosol and Air Quality Research, 20, 2075-2084. https://doi.org/10.4209/aaqr.2020.06.0314.

Bashir, M. F., Jiang, B., Komal, B., Bashir, M. A., Farooq, T. H., Iqbal, N., \& Bashir, M. (2020). Correlation between environmental pollution indicators and COVID-19 pandemic: A brief study in Californian context. Environmental Research, 187, 109652. https://doi.org/10.1016/j.envres.2020.109652.

Bherwani, H., Anjum, S., Kumar, S., Gautam, S., Gupta, A., Kumbhare, H., Anshul, A., \& Kumar, R. (2020). Understanding COVID-19 transmission through Bayesian probabilistic modelling and GIS based Voronoi approach: A policy perspective. Environmental Development and Sustainability. https:// doi.org/10.1007/s10668-020-00849-0.

Bherwani, H., Gautam, S., \& Gupta, A. (2021). Qualitative and quantitative analysis of impact of COVID-19 on sustainable development goals (SDGs) in Indian subcontinent with a focus on air quality. International Journal of Environmental Science and Technology. https://doi.org/10.1007/ s13762-020-03122-z.

Central Pollution Control Board (CPCB). Available in https://cpcb.nic.in/. Assessed on Sep. 3, 2020.

Bukhari, Q., \& Jameel, Y. (2020). Will Coronavirus pandemic diminish by summer? Available at SSRN 3556998. https://doi.org/10.2139/ssrn.3556998.

Chan, C. K., Flagan, R. C., \& Seinfeld, J. H. (1992). Water activities of $\mathrm{NH}_{4} \mathrm{NO}_{3} /\left(\mathrm{NH}_{4}\right)_{2} \mathrm{SO}_{4}$ solutions. Atmospheric Environment, 26A, 1661-1673.

Changotra, R., Rajput, H., Rajput, P., Gautam, S., \& Arora, A. S. (2020). Largest democracy in the world crippled by COVID-19: Current perspective and experience from India. Environmental Development and Sustainability. https://doi.org/10.1007/s10668-020-00963-z.

Chen, G., Zhang, W., Li, S., Williams, G., Liu, C., Morgan, G. G., Jaakkola, J. J., \& Guo, Y. (2017). Is short-term exposure to ambient fine particles associated with measles incidence in China? A Multi-City Study Environmental Research, 156(306), 311.

Chow, J. C., Lowenthal, D. H., Chen, L. W. A., Wang, X., \& Watson, J. G. (2015). Mass reconstruction methods for $\mathrm{PM}_{2.5}$ : A review. Air Quality, Atmosphere \& Health, 8, 243-263.

Coccia, M. (2020). How do low wind speeds and high levels of air pollution support the spread of COVID19? Atmospheric Pollution Research. https://doi.org/10.1016/j.apr.2020.10.002.

Dutheil, F., Baker, J. S., \& Navel, V. (2020). COVID-19 as a factor influencing air pollution? Environmental Pollution, 263, 114466. 
ECDC, European Centre for Disease Prevention and Control (European Union Agency). Situation update worldwide. as of 7 Apr. 2020.https://www.ecdc.europa.eu/en/geographical-distributi on-2019-ncov-cases.

Frontera, A., Cianfanelli, L., Vlachos, K., Landoni, G., \& Cremona, G. (2020). Severe air pollution links to higher mortality in COVID-19 patients: The "double-hit" hypothesis. Journal of Infection, 81, 255-259.

Garg, A., \& Gupta, N. C. (2020). The great smog month and spatial and monthly variation in air quality in ambient air in Delhi, India. Journal of Health and Pollution, 10, 200910. https://doi.org/10.5696/21569614-10.27.200910.

Gautam, A. S., Dilwaliya, N., Shirvastava, A., Kumar, S., Baudda, K., Singh, D., \& Gautam, S. (2020). Temporary reduction in air pollution due to anthropogenic activity switch-of during COVID-19 lockdown in northern parts of India. Environment Development and Sustainability. https://doi.org/10.1007/ s10668-020-00994-6.

Gautam, A. S., Joshi, A., Kumar, S., \& Singh, K. (2020). Short-term impact of weather parameters on COVID-19 cases in 25 states and union territories of India. International Journal of Emerging Technologies, 11, 1-7.

Gautam, S. (2020). The influence of COVID-19 on air quality in India: A boon or inutile. Bulletin of Environmental Contamination and Toxicology, 104, 724-726.

Gautam, S. (2020). COVID-19: Air pollution remains low as people stay at home. Air Quality, Atmosphere \& Health. https://doi.org/10.1007/s11869-020-00842-6.

Gupta, A., Bherwani, H., Gautam, S., Anjum, S., Musugu, K., Kumar, N., Anshul, A., \& Kumar, R. (2020). Air pollution aggravating COVID-19 lethality? Exploration in Asian cities using statistical models. Environment Development and Sustainability. https://doi.org/10.1007/s10668-020-00878-9.

Keary, J., Jennings, S. G., O'Connor, T. C., Mcmanus, B., \& Lee, M. (1998). PM10 concentration measurements in Dublin city. Environmental Monitoring and Assessment. https://doi.org/10.1023/A:10059 35411345.

Kumar, P., Hama, S., Omidvarborna, H., Sharma, A., Sahani, J., Abhijith, K. V., Debele, S. E., ZavalaReyes, J. C., Barwise, Y., \& Tiwari, A. (2020). Temporary reduction in fine particulate matter due to 'anthropogenic emissions switch-off' during COVID-19 lockdown in Indian cities. Sustainable Chemistry and Pharmacy, 62, 102382. https://doi.org/10.1016/j.scs.2020.102382.

Kumar, S., Lin, N., \& Ravindrababu, S. (2020). Association of COVID-19 pandemic with meteorological parameters over Singapore. Science of The Total Environment, 740, 1400112.

Liu, J., Zhou, J., Yao, J., Zhang, X., Li, L., Xu, X., He, X., Wang, B., Fu, S., Niu, T., \& Yan, J. (2020). Impact of meteorological factors on the COVID-19 transmission: A multi-city study in China. Science of the Total Environment. https://doi.org/10.1016/j.scitotenv.2020.138513.

Mahato, S., Pal, S., \& Ghosh, K. G. (2020). Effect of lockdown amid COVID-19 pandemic on air quality of the megacity Delhi, India. Science of The Total Environment, 730, 139086. https://doi.org/10.1016/j. scitotenv.2020.139086.

Maji, S., Ahmed, S., \& Siddiqui, W. A. (2015). Air quality assessment and its relation to potential health impacts in Delhi, India. Current Science., 109, 902-909. https://doi.org/10.18520/v109/i5/902-909.

Mamta, P., \& Bassin, J. (2010). Analysis of ambient air quality using air quality index-a case study. International Journal of Advanced Engineering Technology, 1, 106-114.

Patel, P. N., \& Kumar, R. (2015). Estimation of aerosol characteristics and radiative forcing during dust events over Dehradun. Aerosol and Air Quality Research, 15, 2082-2093. https://doi.org/10.4209/aaqr. 2015.02.0077.

Pathak, R., Yao, X., \& Chan, C. (2004). Sampling artifacts of acidity and ionic species in $\mathrm{PM}_{2.5}$. Environmental Science \& Technology, 38, 254-259.

Sohrabi, C., Alsafi, Z., O’Neill, N., Khan, M., Kerwan, A., Al-Jabir, A., Iosifidis, C., \& Agha, R. (2020). World Health Organization declares global emergency: A review of the 2019 novel coronavirus (COVID-19). International Journal of Surgery, 76, 71-76.

Wang, J., Tang, K., Feng, K., \& Lv, W. (2020). High temperature and high humidity reduce the transmission of COVID-19. SSRN Electronic Journal. https://doi.org/10.2139/ssrn.3551767.

WHO Director (2020). General's Remarks at the Media Briefing on 2019-nCoV on 11 Feb. 2020. https:// www.who.int/dg/speeches/detail/who-director-general-s-remarks-at-the-media-briefing-on-2019-ncovon-11-february-2020.

WHO (2020). https://covid19.who.int/. Last Assessed September 3, 2020.

Wu, F., Zhao, S., Yu, B., Chen, Y. M., Wang, W., Song, Z. G., Hu, Y., Tao, Z. W., Tian, J. H., Pei, Y. Y., \& Yuan, M. L. (2020). A new corona virus associated with human respiratory disease in China. Nature, 579(7798), 265-269. 
Xie, J., \& Zhu, Y. (2020). Association between ambient temperature and COVID-19 infection in 122 cities from China. Science of the Total Environment, 724, 138201. https://doi.org/10.1016/j.scitotenv.2020. 138201.

Xu, B., Gutierrez, B., Mekaru, S., Sewalk, K., Goodwin, L., Loskill, A., Cohn, E. L., Hswen, Y., Hill, S. C., Cobo, M. M., \& Zarebski, A. E. (2020). Epidemiological data from the COVID-19 outbreak, real-time case information. Scientific Data. https://doi.org/10.1038/s41597-020-0448-0ss.

Yadav, S., Praveen, O. D., \& Satsangi, P. G. (2015). The effect of climate and meteorological changes on particulate matter in Pune, India. Environmental monitoring and assessment. https://doi.org/10.1007/ s10661-015-4634-z.

Publisher's Note Springer Nature remains neutral with regard to jurisdictional claims in published maps and institutional affiliations. 